\title{
Benefícios da dança de salão na imagem corporal das mulheres histerectomizadas
}

\author{
Advantage of ballroom dancing in the body image of hysterectomized women \\ Letícia Sampaio Guida ${ }^{\dagger}$ Maria Clara de Mello Andrade:
}

Como citar esse artigo. Guida, L.S; Andrade, M.C.M. Benefícios da dança de salão na imagem corporal das mulheres histerectomizadas. Revista Mosaico 2019 Jul/Dez; 10 (2): SUPLEMENTO $62-67$

\author{
Resumo
}

O presente trabalho tem como objetivo investigar os benefícios da dança de salão em mulheres que realizaram a cirurgia de histerectomia. Esse procedimento pode ser muito desgastante para a maioria das mulheres, uma vez que pode trazer efeitos subjetivos relacionados à sexualidade. A dança de salão pode ser benéfica para quase todas as pessoas, e, principalmente para as mulheres, auxiliando na reconstrução da imagem corporal, refletindo em sua qualidade de vida. Por esse motivo, nas intervenções psicológicas, o profissional de Psicologia pode indicar a suas pacientes histerectomizadas esse tipo de atividade. $\mathrm{O}$ estudo se justifica pelo grande número de mulheres que passam por este tipo de cirurgia e enfrentam toda uma gama de problemas daí advindos, no Brasil e no mundo. $\mathrm{O}$ trabalho foi desenvolvido por meio de revisão de literatura numa abordagem qualitativa, observando que a dança de salão contribui para que a mulher tenha uma melhor qualidade de vida, desenvolvendo uma autoimagem mais favorável.

Palavras-chave: Dança de salão, Histerectomia, Imagem corporal.

\begin{abstract}
The present study aims to investigate the benefits of salon dancing in women who underwent hysterectomy surgery. This procedure can be very stressful for most women, since it can have subjective effects related to sexuality. Ballroom dancing can be beneficial for almost all people, and especially for the women, aiding in the reconstruction of body image, reflecting on their quality of life. For that reason in the psychological interventions, the professional of Psychology must indicate to his hysterectomized patients this type of activity. The study is justified, therefore, is very large the number of women who suffer this type of surgery and face a whole range of problems from there arising in Brazil and the world. The work was developed through literature review in a qualitative approach, observing that the ballroom dance contributes to the woman having a better quality of life, developing a more favorable self-image.

Keywords: Ballroom dance; Hysterectomy; Body image.
\end{abstract}

\section{Introdução}

A histerectomia trata-se da remoção cirúrgica do útero, que pode acontecer por via abdominal ou vaginal. De acordo com dados do Departamento de Informática do Sistema Único de Saúde -SUS - (DATASUS, 2012), no Brasil, a cada ano, cerca de 300 mil mulheres fazem cirurgia de histerectomia.

O útero é um órgão que está biologicamente associado à reprodução e socialmente associado à feminilidade e sexualidade. Assim sendo, sua extirpação pode constituir-se num ato agressivo e mutilante, podendo também interferir na sexualidade feminina, na imagem corporal e na vida social da mulher (SBROGGIO; OSIS; BEDONE, 2005).

Villar e Silva (2009) assinalam que a retirada do útero pode ocasionar uma série de prejuízos na qualidade da vida sexual da mulher, nas suas condições emocionais e também na qualidade do seu relacionamento com o parceiro. A necessidade de realização da cirurgia provoca, em muitos casos, uma série de emoções conflitivas, traumatizantes, de ansiedade e insegurança, gerando mudanças significativas no comportamento da mulher.

A imagem corporal é elaborada de maneira multidimensional pelo indivíduo ao longo do seu processo de desenvolvimento, constituindo-se na base construtiva para a formação do conceito de si próprio. Dessa maneira, além da percepção, a imagem corporal abarca elementos comportamentais, cognitivos e afetivos e a alteração da imagem irá interferir diretamente nos pensamentos, emoções e relacionamentos (CASH;

Afiliação dos autores: $\uparrow$ Acadêmica do Curso de Psicologia da Universidade de Vassouras - RJ - Brasil

\$ Mestre em Psicologia - Professora do Curso de Psicologia da Universidade de Vassouras - RJ - Brasil

* Email de correspondencia: leticiaguida@gmail.com 
PRUZINSKY, 2004).

O estudo parte do seguinte problema de pesquisa: Que benefícios a dança de salão pode trazer na imagem corporal e, consequente, qualidade de vida das mulheres histerectomizadas?

A dança faz parte da natureza humana, pois tratase de uma manifestação instintiva, podendo ser definida como "a arte de mover o corpo em um determinado ritmo, expressando sentimentos e emoções através de movimentos" (TONELI, 2007, p.13).

$\mathrm{Na}$ concepção de Hass e Garcia (2006, p.139), "entende-se a dança como uma arte que significa expressões gestuais e faciais através de movimentos corporais, emoções sentidas a partir de determinado estado de espírito". Nesta perspectiva, os autores complementam que a dança é uma maneira de comunicar e expressar as emoções humanas.

A dança de salão integra diversos aspectos positivos, uma vez que sua prática atinge os domínios: psicomotor, socioafetivo e perceptivo cognitivo, estando relacionada à melhoria da coordenação motora, do ritmo, da percepção espacial do desenvolvimento da musculatura e também da autoestima, possibilitando o convívio e o aumento das relações sociais e a quebra de diversos bloqueios psicológicos, como, por exemplo, a timidez (ABREU; PEREIRA; KESSLER, 2008).

O objetivo do presente estudo é avaliar a importância da prática da dança de salão na imagem corporal das mulheres que passaram por cirurgia de histerectomia. Para tanto, vai-se discorrer a respeito da cirurgia de histerectomia e suas implicações na vida da mulher, vai-se falar sobre dança de salão e seus benefícios para uma melhor qualidade de vida das mulheres histerectomizadas.

Além disso, busca esclarecer como a dança de salão pode contribuir na imagem corporal das mulheres que passaram por cirurgia de histerectomia, objetivandose estudar e compreender de que maneira tal modalidade de dança proporcionará a essas mulheres uma melhor qualidade de vida.

O artigo foi desenvolvido por meio de revisão de literatura. Esse tipo de pesquisa foi utilizado, pois conforme Minayo (2008, p.53), ela norteia, subsidia e dá consistência teórica ao trabalho, colocando "frente a frente os desejos do pesquisador e os autores envolvidos em seu horizonte de interesse".

\section{Repercussão da histerectomia para as mulheres}

Alguns profissionais de saúde não consideram os efeitos da cirurgia de histerectomia na vida da mulher, que "terá removido seu útero, órgão intimamente relacionado com identificação/definição de seu papel feminino na sociedade”. Silva, Santos e Vargens (2010, p.77). Pois, estes profissionais adotam a ideia de que o tratamento de um corpo físico doente, deve ter "como principal foco as questões biológicas, relegando a um segundo plano a subjetividade do ser-mulher".

Sobre este fato Sbroggio (2008) discorre que:

A maioria dos ginecologistas acredita que este procedimento traria consequência de pequena monta para as mulheres, restringindo-se apenas à perda da capacidade reprodutiva e ao cessamento das menstruações. Diante de uma prole já constituída, seria basicamente indiferente para o casal (SBROGGIO, 2008, p. 22).

No entanto, diante da notícia que "terá este órgão extirpado, a mulher passa minimamente por dois tipos de problemas: o medo da cirurgia propriamente dita e da mutilação de um órgão que representa a maternidade e de certa forma sexualidade feminina" (SILVA; SANTOS; VARGENS, 2010, p. 77).

De acordo com Salvador, Vargens e Progianti (2008), os efeitos da histerectomia para a mulher, mais especificamente no que concerne à sua sexualidade, são complexos e decorrem de fatores físicos, psicológicos, culturais, sociais, religiosos e educacionais, que causam interferência na visão que a mulher possui do útero e de si mesma. Para os autores:

Essa mudança é dependente de crenças e valores que esta mulher possui, relacionados ao útero e ao gênero feminino. Essas crenças e valores, por sua vez, são oriundos da interação da mulher com uma sociedade marcada pelo sistema patriarcal que, valorizando a maternidade como aspecto essencial em sua vida, confere ao útero um sentido de fornecedor de identidade à mulher, sendo necessário à confirmação de sua feminilidade (SALVADOR; VARGENS; PROGIANTI, 2008, p. 321).

Assim, segundo as autoras acima, a retirada do útero faz com que as mulheres, frequentemente, vivenciem situações de anseios e questionamentos ligados a crenças e valores, que induzem a reformulações baseadas na própria feminilidade, no social, no gênero, na autoimagem, na sexualidade e na relação social e conjugal.

Sbroggio, Giraldo e Gonçalves (2008) discorrem que o útero, além de sua função biológica, está diretamente associado ao conceito de feminilidade, uma vez que está relacionado ao papel reprodutor da mulher e também à sua vida sexual. Essa associação se justifica, pois, a remoção do órgão pode se refletir na libido e no desejo sexual. Ainda segundo os autores:

Essa associação já foi observada em mulheres portadoras de patologias uterinas, no momento da necessidade da retirada do útero. Essas mulheres sofreram abalo em sua identidade feminina porque, para elas, o útero além de simbolizar sua capacidade sexual, garante também a sua feminilidade. Após a sua retirada, as mulheres 
passaram a se sentirem diminuídas, pois acreditavam estarem incapacitadas sexualmente para o prazer (SBROGGIO; GIRALDO; GONÇALVES, 2008, p.260).

O conceito de feminilidade associado ao útero é muito antigo. Apesar de terem sido construídos uma série de significados em torno do conceito de feminilidade, a maior parte deles relevam o papel da mulher enquanto reprodutora, ou seja, restringe a razão da sua existência à maternidade (SBROGGIO; GIRALDO; GONÇALVES, 2008). Assim:

As ideias aprendidas pelas mulheres quanto ao seu corpo e aos órgãos sexuais externos e internos acabavam intimamente atrelados ao propósito social de exercer controle sobre a sexualidade delas, utilizando como justificativa a necessidade de preservá-las para a maternidade, vista como a única área em que as mulheres tinham a missão social, a de preservar a espécie, produzindo filhos sadios (SBROGGIO; GIRALDO; GONÇALVES, 2008, p.261).

Por esse motivo parte das mulheres histerectomizadas sentem-se ameaçadas quanto à própria sexualidade, frigidez e perda de parceiro. Historicamente foi construído um conceito que associa o útero à feminilidade, e a remoção do órgão pode acabar por representar a perda do seu valor simbólico e real.

Dessa maneira, pode-se identificar que o autoconceito e a imagem corporal passam a estar associados à antecipação da menopausa, que, para a grande maioria das mulheres, tem o significado de um período difícil, de crise e de muitas perdas. No mundo ocidental, parar de menstruar pode significar perder a juventude, a beleza física, e a possibilidade da maternidade, ou seja, perder aspectos indispensáveis para a valorização da feminilidade (SBROGGIO, 2008).

\section{Intervenção psicológica para mulheres histerectomizadas}

A histerectomia, além de se tratar de uma intervenção cirúrgica bastante invasiva, trata-se de um procedimento cheio de crenças a respeito da perda de feminilidade, atingindo de maneira prejudicial a autoestima feminina.

A intervenção psicológica deve ocorrer durante todo o período, uma vez que no pré-operatório grande parte das mulheres passam por uma sensação de temor e desespero, por acreditarem que irão tornar-se diferentes, menos femininas e até mesmo frígidas (SALVADOR; VARGENS; PROGIANTI, 2008).

Jamarino (2009) descreve que as mulheres que devem passar por cirurgia de histerectomia, temem a morte, o procedimento, a anestesia e a recuperação. Muitas delas, tentando obter controle sobre esses medos, lançam mão de estratégias, como: depositar inteira confiança na equipe de saúde; passar a ter uma crença acentuada em Deus; buscar o controle do pensamento e ter sempre a companhia de alguém amado.

Dentro desse contexto, a intervenção psicológica é importante, principalmente quando trabalhada de maneira multidisciplinar, em comunicação com outros profissionais da saúde, que também atuam com essas pacientes. Todos juntos devem buscar minimizar a dor, aliviar dúvidas e auxiliar nos enfrentamentos aos eventos estressores (JAMARINO, 2009).

No que concerne ao profissional de Psicologia, inserido nesse contexto, Ferreira e Lemos (2016) apontam que este pode atuar acolhendo e dando suporte à paciente e seus familiares, sempre procurando esclarecer as dúvidas do pré e pós-operatório, objetivando contribuir para que o procedimento seja realizado com maiores chances de sucesso.

Assim, o psicólogo pode indicar para suas pacientes pós-operadas, clinicamente saudáveis, a dança de salão, evidenciando para as mesmas os benefícios que este tipo de atividade pode trazer para suas vidas. Melhorando sua autoestima, elevando sua autoimagem e sua qualidade de vida.

\section{Dança de Salão}

A dança de salão surgiu no século $\mathrm{XV}$, representando uma dança social, fazendo parte de encontro de nobres em seus salões e objetivando a educação aristocrática da época. No Brasil, chegou no século XVI através de colonizadores portugueses e imigrantes de países da Europa. Atualmente, está tendo um destaque maior como atividade física que proporciona bem-estar e melhoria na qualidade de vida dos praticantes (GAION, 2011).

A dança de salão é uma atividade onde pode ser associado atividade física, convívio social, diversão e aprendizado. A dança de salão tem potencial para produzir vários efeitos nas pessoas, principalmente o prazer, que sem a menor sombra de dúvidas é um dos motivos mais relevantes que levam adultos e adolescentes à prática. Muitos buscam a dança de salão para se divertir, fugir dos problemas (GAION, 2011).

As pessoas acabam procurando este tipo de dança devido à propaganda. De acordo com Toneli (2007), a mídia tem contribuído, mostrando que a dança promove o bem-estar de quem a pratica. Além disso, os aspectos fisiológicos, emocionais e sociais também são relevantes.

Quanto ao aspecto fisiológico, observa-se que os praticantes sentem seus corpos mais leves, e seus movimentos mais apurados, tornando os indivíduos mais dispostos e com maior ânimo de realizar as coisas. Emocionalmente, pode-se constatar que a dança de salão é contagiante; nela as alegrias e emoções se afloram, 
muitos problemas são esquecidos, há uma sensível melhora na autoestima, e as pessoas sentem-se mais felizes. Os corpos dos dançarinos pedem para dançar, quando ouvem uma música, ou quando veem o outro dançando. Esse aspecto social da dança proporciona uma melhor interação entre as pessoas, fazendo-as sentir mais seguras e mais equilibradas emocionalmente (TONELI, 2007).

Nos últimos anos a dança de salão vem tomando lugar de destaque como uma atividade física que proporciona bem-estar e melhoria na qualidade de vida dos praticantes de diversas faixas etárias. Entre os benefícios destacam-se a melhora na coordenação motora, ritmo, memória, flexibilidade, equilíbrio, concentração, resistência e força muscular, postura e a consciência corporal. A dança de salão produz também melhorias nas funções vitais do organismo como digestão, respiração e circulação, enfatizando-se o condicionamento cardiorrespiratório (SHIBUKAWA et al., 2011).

Ellmerich (2007) aponta que a dança de salão traz uma série de benefícios para os seus praticantes, que vão além de se movimentar no tempo da música. A dança de salão possibilita socializações, melhora a autoestima e autoconfiança, serve como uma válvula de escape para as frustrações do dia a dia, além disso, é capaz de fazer com que uma pessoa sedentária passe a realizar um ótimo exercício cardiovascular, além de corrigir a sua postura.

Santana, Corradini e Carneiro (2009) assinalam que a dança de salão trabalha harmonicamente o corpo todo, deixando-o saudável e bonito, aumentando a autoestima. Desta forma, combate ao estresse, gerando bem-estar, além de entreter de maneira prazerosa, trazendo desenvoltura ao praticante, favorecendo sua socialização.

\section{Dança de salão e a percepção corporal}

Dois aspectos podem ser considerados como formadores da percepção corporal de um indivíduo: o esquema corporal, no que se refere à concepção neurológica e a imagem corporal ligada ao lado psicológico.

A imagem corporal está ligada às diversas maneiras que o indivíduo experimenta e conceitua seu próprio corpo, por meio da representação mental da figura do corpo humano. Ou seja, trata-se de uma construção mental do próprio corpo, partindo-se "de impressões subjetivas e juízo de valores sendo moldada pelas experiências individuais, relações sociais e cultura" (ALMEIDA, 2005, p.130).

$\mathrm{Na}$ concepção de Fonseca, Vecchi e Gama (2012):

\begin{abstract}
É um fenômeno singular estruturado na experiência existencial do ser humano consigo mesmo, com as outras pessoas e com o universo, resultante da interação dinâmica entre a percepção e a concepção. Como a cada instante ocorre uma nova percepção, e, por ser influenciada a todo momento pelos estados emocionais, conflitos psíquicos, interação com outros seres, a imagem corporal tem característica de ser lábil e mutante (FONSECA; VECCHI; GAMA, 2012, p. 203).
\end{abstract}

Assim sendo, quando a mulher movimenta seu corpo, explorando diversas possibilidades espaciais e articulares, juntamente com um parceiro, obedecendo um ritmo musical, combinando com a fluidez mental e com a explosão de emoções proporcionadas pela dança, estará desenvolvendo uma relação com seu corpo e com o corpo do outro, assim como, com as demais pessoas e objetos a sua volta. Dessa maneira, conforme destacam Fonseca, Vecchi e Gama (2012, p.202), "evoluir na dança pode significar desenvolverse como pessoa". Além disso, defendem que a dança de salão pode ser considerada como "uma maneira de produzir alterações positivas na relação mente-corpo, modificando a percepção corporal, tanto no seu aspecto proprioceptivo (esquema corporal) como no aspecto emocional (imagem corporal)".

O estudo de Zaniboni e Carvalho (2007) avalia que a prática de dança faz com que as mulheres passem a ter uma imagem corporal positiva, uma vez que as dançarinas possuem um maior grau de satisfação corporal do que as mulheres que não praticam dança.

Fonseca, Vecchi e Gama (2012, p.204) observam que a dança traz benefícios para a autoimagem, pois através "do movimento e experimentação do corpo os indivíduos estruturam a experiência de si mesmos no mundo e promovem resgate de sentimentos subconscientes oprimidos que interferem de forma positiva na imagem corporal".

A dança desperta a linguagem corporal, muitas vezes não experienciada em outras atividades físicas, que pode ser utilizada como uma poderosa ferramenta na expressão de sentimentos e emoções. No caso da dança de salão, a interação com o parceiro, faz com que seja estabelecido um diálogo entre ambos e com o exterior. Dessa maneira, dançar é "uma maneira dos indivíduos estruturarem sua experiência de si mesmas no mundo através do movimento e promover o resgate de sentimentos subconscientes oprimidos, provocando efeitos positivos na imagem corporal" (FONSECA; VECCHI; GAMA,2012, p.203).

A dança de salão oportuniza o desenvolvimento da própria imagem a partir da experiência com o outro. Para Zaniboni e Carvalho (2007, p.89) "o estreitamento do vínculo entre os sujeitos e a interlocução dos corpos proporciona a (re)construção da imagem corporal".

Assim, pode-se observar que a dança de salão é um espaço de interação entre os corpos além de constituir- 
se numa prática que facilita a construção da imagem corporal dos indivíduos. Rosa Neto (2009) defende que o corpo torna concreta a existência do ser humano, pois possibilita que o indivíduo se perceba e que seja percebido, numa interação com o mundo exterior.

Para o autor acima citado, "qualquer movimento executado pelo indivíduo pode modificar a sua imagem corporal; ao mesmo tempo a imagem corporal ira imprimir características individuais e circunstanciais à realização de qualquer movimento executado pelo indivíduo" (ROSA NETO, 2009, p.45).

Nesta perspectiva, acredita-se que a mulher histerectomizada poderá ter mais oportunidade de preservar sua autoimagem por meio da interação com outras pessoas, de contatos com amigos, conversas e a diversão da dança, mantendo assim, seus estados motivacionais internos e uma imagem corporal positiva.

No que se refere à autoestima pode-se comprovar em Zaniboni e Carvalho (2007) que a autoestima pode ser considerada uma chave para o entendimento dos seres humanos, tratando-se da soma da autoconfiança com o autorrespeito. É um sentimento que não nasce com o indivíduo, mas pode ser desenvolvido durante a sua vida. Neste contexto, conforme pontuam os autores, a dança de salão pode trazer estas descobertas uma vez que objetiva a socialização, a descontração, desinibição, quebra de conflitos do cotidiano, proporcionando momentos de alegria, liberdade, euforia e poder, à medida que se possibilita a transcendência dos limites do corpo.

\section{Considerações Finais}

Observou-se por meio dos autores analisados que a histerectomia pode trazer uma série de consequências para a vida da mulher, principalmente no que se refere ao aspecto psicológico, uma vez que a retirada do útero pode ser compreendida como o final de um ciclo na vida da mesma.

Verificou-se também que a maioria dos ginecologistas encaram a operação como uma atividade de rotina, sem atentar para os estragos que a mesma pode acarretar para a vida das mulheres. Acreditam que a extirpação de um órgão doente se trata somente de um benefício.

Compreendeu-se que a personalidade do indivíduo pode se expressar em suas atividades diárias. A dança é uma expressão dos sentimentos através dos movimentos. Quando se evolui na dança podese evoluir como pessoa. Neste sentido, observou-se que a dança de salão pode ser muito benéfica para a maioria das pessoas, e, em se tratando de mulheres histerectomizadas, pode auxiliar na construção de uma percepção corporal mais positiva. Além disso, contribui para que a mulher tenha uma melhor qualidade de vida e cultive uma autoimagem mais favorável. Por esse motivo, nas intervenções psicológicas, com mulheres histerectomizadas, o profissional de Psicologia pode incentivar suas pacientes para as práticas de dança de salão.

Defende-se aqui a ideia de que novos artigos devam ser elaborados, uma vez que, na pesquisa realizada não foi encontrada nenhuma referência que trate diretamente do tema proposto. Dessa maneira, novos estudos devem ser desenvolvidos no sentido de se compreender melhor os benefícios da dança de salão para as mulheres que passaram pelo processo de histerectomia, principalmente no que concerne aos benefícios psicológicos dessa prática.

\section{Referências}

ABREU Everton Vieira; PEREIRA, Luciene Therezinha Zermiani; KESSLER, Edio José. Timidez e motivação em indivíduos praticantes de dança de salão. Revista Conexões; v.6, p.21-33, 2008.

ALMEIDA, Cleuza Maria de. Um Olhar sobre a Prática da Dança de Salão. Movimento e Percepção, Espírito Santo do Pinhal, v.5, n.6, p.129-134, 2005.

CASH, Thomas F; PRUZINSKY, Thomas. (ed.) Body image:A handbook of theory, research, and clinical practice. New York: Guilford Publications, 2004.

DATASUS (Departamento de Informática do SUS), Sistema de Informações Hospitalares do SUS (SIH/ SUS). (2012). Disponível em: http://www. datasus.gov.br. Acesso em: 25 jan. 2019.

ELLMERICH, Luís. História da Dança. São Paulo: Nacional, 2007.

FONSECA, Cristiane Costa; GAMA, Eliane Florencio. Esquema Corporal, Imagem Corporal e Aspectos Motivacionais na Dança de Salão. Dissertação de Mestrado em Educação Física - Faculdade de Educação Física, Universidade São Judas Tadeu, São Paulo, 2008.

FONSECA, Cristiane Costa; VECCHI, Rodrigo Luiz; GAMA, Eliane Florêncio. A influência da dança de salão na percepção corporal. Motriz, Rio Claro, v.18 n.1, p.200-207, jan./mar. 2012.

GAION, Aparecida Bernadete. Dança de Salão: Qualidade de vida e integração. 2011. Disponível em: http://web.unifil.br/docs/extensao/II/20 Danca\%20de\%20salao.pdf. Acesso em: 29 jan. 2019

HASS, Aline Nogueira; GARCIA, Ângela. Ritmo e dança. Canoas. Ed. ULBRA, 2006

JAMARINO, Amanda Maria. Análise da percepção corporal e sexual de mulheres histerectomizadas. Trabalho de Conclusão de Curso. Enfermagem. Centro Regional Universitário de Espírito Santo do Pinhal, SP, 2009.

MINAYO, Maria Cecília de Souza (Org.). Pesquisa social: teoria, método e criatividade. Petrópolis, RJ: Vozes, 2008.

ROSA NETO, Armindo. Imagem Corporal, Esquema Corporal e Destreza Manual em Adolescentes Deficientes Visuais. Dissertação de Mestrado em Educação Física - Faculdade de Educação Física, Universidade São Judas Tadeu, São Paulo, 2009.

SALVADOR, Rachel Torres; VARGENS, Octávio Muniz da Costa, PROGIANTI, Jane Márcia. Sexualidade e histerectomia: mitos e realidade. Rev Gaucha Enferm.; v.29, n.2, p. 320-323, 2008.

SANTANA, Susana; CORRADINI, Amanda; CARNEIRO, Roberta Helena. A dança de salão e seus benefícios motores, cognitivos e sociais. Anuário da produção de iniciação cientifica discente; v.12, n.15, p.83-104, 2009.

SBROGGIO, Adriana Magrin Rivera; OSIS, Maria José Martins Duarte; BEDONE, Aloísio José. O significado da retirada do útero para as mulheres: 
um estudo qualitativo. Rev Assoc Med Bras.; v.51, n.5, p.270-274, 2005.

SBROGGIO, Adriana Magrin Rivera. Autopercepção corpórea e sexual de mulheres submetidas à histerectomia. Tese de Doutorado. Unicamp, Campinas, SP, 2008.

SBROGGIO, Adriana Magrin Rivera; GIRALDO, Paulo César; GONÇALVES, Ana Katherine da Silveira. A preservação da feminilidade após a remoção do útero. Revista Moreira JR; v.12, n.5, p.260-263, 2008.

SHIBUKAWA, Rodrigo Massami et al. Motivos da Prática de Dança de Salão em Escolas Particulares. Rev. bras. Educ. Fís. Esporte, São Paulo, v.25, n.1, p.19-26, jan./mar. 2011

SILVA, Carolina de Mendonça Coutinho; SANTOS, Inês Maria Meneses dos; VARGENS, Octávio Muniz da Costa. A repercussão da histerectomia na vida de mulheres em idade reprodutiva. Esc Anna Nery Rev Enferm; v.14, n.1, p.76-82, jan-mar 2010.

TONELI, Poliana Dutra. Dança de salão: instrumento para a qualidade de vida no trabalho. Bacharelato em Administração. Instituto Municipal de Ensino Superior de Assis, Assis, São Paulo, 2007.

VILLAR, Alana; SILVA, Leila. Os sentimentos de mulheres submetidas à histerectomia e a interferência na saúde sexual. Revista de Pesquisa Cuidado é Fundamental Online; v.27, n.6, 2009.

ZANIBONI, Lilian; CARVALHO, Armando Gonçalves. Dança de Salão: Uma Possibilidade de Linguagem, Revista Conexões, Campinas, v.5, n.1, p.86-102, 2007. 